\title{
Engagement in Practice: Learning Applications of MSE for Design of Community Based Shelter for Housing Insecurity
}

\author{
Dr. Ajay P. Malshe, Purdue University
}

Dr. Malshe is a R. Eugene and Susie E. Goodson Distinguished Professor of Mechanical Engineering and the Director of the Materials and Manufacturing Research Laboratory (MMRL), Purdue University. His fields of academic and industrial interest are advanced manufacturing, food-shelter-clothing and related life insecurities, bio-inspired materials and designing and system integration. He has overlapping 24 years of academic plus overlapping 15 years of industrial entrepreneurship experience. Application areas of his interest are food and agriculture manufacturing, mechanical systems, and manufacturing in space. He has 225 peer-reviewed publications and has delivered 105 keynote and invited talks across the United States and the world. He has 22 allowed patents with more than 65 resulting products commercialized and launched, in a team, across many industrial sectors worldwide used by Fortune 500 companies in the energy, electric vehicle, heavy-duty trucking, railway transportation, and high performance race car sectors. Malshe has trained 67 graduate and post-doctoral students and more than 1250 undergraduate students and young professional engineers in industries. He has also worked extensively with high schools to advance student learning success. Malshe's notable honors include: Membership in the National Academy of Engineering (NAE) for "For innovations in nanomanufacturing with impact in multiple industry sectors"; Society of Manufacturing (SME)'s David Dornfeld Blue Sky Manufacturing Idea Award for "FactoriesIn-Space"; SME-S.M. Wu Research Implementation Award; three Edison Awards for Innovation; Tibbett Award by the US Small Business Association sponsored by EPA for successful technology transfer; R\&D 100 Award, (the "Oscar" of innovation); Fellowships to the International 1. Academy of Production Engineering (CIRP), 2. the American Society of Materials (ASM), 3. the American Society of Mechanical Engineering (ASME), and 4. the Institute of Physics (IoP), London, England; multiple best paper awards; NanoBusiness Alliances' Lifetime Achievement Award and Most Influential Nanotechnology Leaders award; and Special recognition under "Discoveries" from NSF for a new process, "Electric Pen Lithography (EPL) for sub-20 nm scale machining using nanoEDM".

\section{Dr. Kevin M Fitzpatrick, University of Arkansas}

Kevin M. Fitzpatrick, $\mathrm{PhD}$, is a community sociologist with 35 years of experience as a researcher, consultant, and advocate. Kevin is a University Professor in the Department of Sociology and Criminology at the University of Arkansas. Since 2005, he has devoted the majority of his work-focus on helping communities throughout Arkansas better understand the challenges they face, and the types of strategies they might consider adopting to address those challenges. He has published 5 books and more than 75 peer-reviewed articles and book chapters that have continually emphasized the theme that place matters. Dr. Fitzpatrick is currently working with a multi-disciplinary team to develop technological innovations to address place-based food insecurity.

\section{Dr. Salil Bapat, Purdue University}

Dr. Salil Bapat is currently a Post-doctoral Research Associate in the Department of Mechanical Engineering at the Purdue University under the mentoring of Prof. Ajay P. Malshe since March 2020. Dr. Bapat holds a Ph.D. degree in Microelectronics-photonics from University of Arkansas with emphasis on 'tribology and surface characterization'. He has master's and bachelor's degree in Materials Science and engineering with experience in semiconductors, thin films processing and materials characterization. $\mathrm{He}$ has been involved with Prof. Malshe in teaching the introduction to materials class at the University of Arkansas for last 5 years in the capacity of teaching assistant, co-instructor and instructor. 


\title{
Community Engagement in Practice: Learning Applications of MSEM in Developing Alternative Housing Designs for Addressing Homelessness
}

\author{
Ajay. Malshe*, ${ }^{* 1}$ Kevin Fitzpatrick ${ }^{2}$ and Salil Bapat ${ }^{1}$ \\ ${ }^{1}$ School of Mechanical Engineering, Purdue University, West Lafayette, IN, USA \\ ${ }^{2}$ Department of Sociology and Criminology, University of Arkansas, Fayetteville, AR, USA \\ *Presenting and corresponding author: amalshe@purdue.edu
}

\begin{abstract}
Homelessness/ housing insecurity is a growing challenge across the US and the world. Students, especially Gen-Z, are about to enter the workforce where insecurities including housing insecurity are common observations in daily life. Generating engineering student's awareness of housing insecurity was the key objective of the presented work as a part of Introduction to Materials Science and Engineering, and manufacturing (MSEM) class in the mechanical and industrial engineering curriculum. A team of a social scientist, mechanical and manufacturing engineer and materials engineer teamed in the summer of 2018 to design a project where a class of 83 students would undertake a project in the Fall 2018 semester. The goal of the project was to apply the understanding of the material's structure-property-applications relationships to identify specific materials for meeting engineering specifications for various components of community housing in Northwest Arkansas (NWA). The housing designs were produced by architects in close collaboration with a social scientist. Examples of various housing design components included material recommendations for kitchen tents, bathroom shower flooring, outdoor community decks, common area kitchen tops, and others. Each design component was delegated to 3 groups with 3 students per group to recommend materials for very high durability, simplicity of installation and low price for frugal engineering. Through this process, students: 1) developed an understanding of a growing major societal problem in America as they were asked to visit and get familiarized with the problem; and 2) studied the architectural components for developing application-specific material/product recommendations using the structure of a material, desired properties, commercial availability, pricing and recommended vendors. This was approximately an 8-week long exercise whereby students submitted their recommendations in a team report, later submitted to the team of the social scientist and the architect. This paper would detail the results of this phase-I project and the implantation model.
\end{abstract}

\section{Introduction:}

Over the last two decades, materials science and engineering, and manufacturing (MSEM) has evolved into an important, interdisciplinary subject area in the engineering curriculum [1][3]. As a result, introductory undergraduate level MSEM class (with or without lab component) has become part of traditional non-MSEM engineering programs such as mechanical and industrial engineering. In some cases, this type of class is a required component of an undergraduate course curriculum. Covering the depth and breadth of an interdisciplinary and 
hands-on subject like MSEM in a single semester presents a significant challenge in terms of engaging non-MSEM students throughout the semester. The authors have previously reported successful implementation of a pedagogical approach involving a project component [4] where the students picked the material for research-based learning based on their hobbies or personal interests. The motivation behind this approach was to encourage and engage students in curiosity-driven project-based learning within the framework of concepts discussed in the class. To advance the approach further, a central theme, focusing on a critical social problem, was implemented as a strategy for creating more social awareness, clarity, uniformity, and potential outreach impact to class assignments.

The objective of this project was to understand the utilization of structure-property-material manufacturing process-application of the materials and its implementation for a specific community-based project in NWA, aimed at working on alternative housing designs to address sheltering needs of a chronic homeless population. This process required students to understand the 'structure-property-processing-performance' and apply the learning for a specific engineering application/component within the constraints of design, function and cost and manufacturing. At the same time, students were introduced to the topic of housing and homelessness by our community partners to help them better understand the specific needs and importance of developing housing alternatives to this special needs population.

The motivation of this project is the converging application of fundamental engineering learning for social engineering. As both visible and invisible homeless sub-populations continue to grow in the United States in the midst of a growing housing crisis related to both access and affordability, alternative strategies for housing and materials design are critical. Social scientists and community partners continue to look for alternatives to traditional housing and are actively finding ways to address these complicated needs. The piloted class, where the students are learning structure, resultant properties of materials and processes for a diverse set of applications, adopted a specific social problem to identify and work on strategies using a theoretical and practice-based engineering solution. At the same time, students were exposed to lectures and extensive resources to help them better understand the population, the problem, and the challenges related to finding secure and safe housing for chronic homeless persons.

As a result of this semester-long process, this pilot project brought together sociology, a local homeless service provider, community design center, mechanical engineering professor, and MSEM students to 1) coalesce around a common theme and work together in teams to apply their classroom learning to identify specific materials for various parts of alternative housing designs for engineering specifications, and 2) develop classroom materials to help students better understand the manufacturing and commercial feasibility of the proposed materials as well as the practical application of and utility in those proposals for usage in housing construction.

\section{Syllabus and Scope of the class:}

In the scope of the MSEM class [5], students studied the physical and chemical properties of materials using an application-driven approach. The materials of interest were: metals, polymers, ceramics, and composites. Students learned the interactive relationship between structure, properties, and processing of materials emphasized for various engineering applications. Along 
with this textbook, students had access to the materials design and selection software [6]. Following were the key topics for the class:

1) Introduction to different types of materials for conventional and modern industrial product applications with an emphasis on "application-specific materials' selection for engineered part(s) or system(s)"; 2) Study application intended interactive relationship between material structure, properties, behavior, and processing of materials; 3) Introduction to metals, polymers, ceramics, (and composites); and 4) Introduction to techniques for materials processing and testing.

Overall the final project report was weighed for $10 \%$ of the final total grade.

\section{Project details and execution:}

The project was implemented over a 6-week long period where students developed their solution in parallel with the classroom discussion on materials properties, materials selection, and materials processing. During the middle of the semester, students were provided with clear instructions and expectations about the project through classroom discussions and the homework assignment dedicated to the project. Also, students received an entire class period of lecture and discussion around the topics of housing and homelessness. More importantly, our partner in sociology had extensive experience in working with local non-profits throughout the region and is currently leading a design and implementation team to build temporary housing for the chronic homeless population in the region. The class was divided into groups (an average of three students per group) to execute the project. Each group was assigned a specific component of the alternative housing design as their component/material for research. These components included:

1) glass panels for windows and walls; 2) indoor flooring; 3) kitchen/ warming tent; 4) outdoor flooring with no shades; 5) interior bathroom shower floors; 6) outdoor flooring under shade; 7) all-weather fabric roof covering; and 8) outdoor walkways.

After the formation of the teams, a homework assignment was developed and distributed to the class. The purpose of this assignment was to get students to familiarize themselves with the problem, study the application-specific design component assigned to them as a team, and build a framework for their final project report. The assignment was divided into the following four sections listed below with their intended purpose:

As a form of constructive feedback, the homework assignments were graded for their readiness to be implemented as a class project. The purpose of this feedback was to ensure that the corrective actions (if required) regarding the choice of materials, details of the design/property requirements and overall depth of the project were communicated to the groups well in advance to the final submission deadline. Throughout the remainder of the semester, the instructor and the teaching team were accessible during the drill, office hours and by appointment for discussion and providing guidance.

Students were asked to submit their final report in the form of a ring-bound hard copy along with a soft copy of the PowerPoint slides. As per the project rubric, the report was comprised of the following outlined sections covering various aspects of materials science and engineering and its application to the proposed solution addressing the social problem:

1) Currently selected component application; 2) Material part specifications; 3) Desired Material Properties \& Functionalities; 4) Structures; 5) Design considerations, 6) Manufacturing 
process sequence; 7) Manufacturers and pricing; 8) New suggested applications (at least two); 9) Material Properties \& Application Design considerations; and 10) References.

\section{Outcomes and conclusion:}

The report submissions were graded based on their depth, detailed discussion, and recommendations that made the practical connection between classroom learning and the need for alternative housing designs. The reports were graded by the instructor and the director of the community engagement segment of the program. An example of a report that received the highest grade is shown in Figure 1 below. For each component application, the top-graded report(s) were selected and delivered for sharing with the design architects who were responsible for proposing a range of options to the construction team as they prepared drawings and construction estimates. Overall, the recommendations received positive feedback from the design architects and the community engagement team. Several conversations took place between the community partners, architects, and the social science team member. All reports indicated that the proposals that were generated by this highly engaged class had generated an important set of design and build considerations.

To summarize, as a class, the "adopt-a-material for alternative housing strategies for homeless populations" project was successfully implemented where students studied and recommended specific engineered material for various components of a chronic homeless program and shelter that specifically was designed by the architects to address the complicated and varied needs of the homeless population in the local community. Students recommended these materials using knowledge regarding their intended applications (e.g. a canvas tent for the common kitchen area, an outdoor walkway in the shade, multi-purpose flooring, bathroom fixtures, etc.), desired functional demands on the application and desired properties along with material's structure. Finally, students included in the report how these solutions would be manufactured and where and for how these material solutions could be purchased. We believe that this piloted class provided an excellent hands-on experience for students to apply classroom learning to a critical social problem in the form of social innovation.

\section{Acknowledgments:}

The authors (SB and APM) acknowledge the support from the 21st Century Endowed Chair Professorship fund, University of Arkansas where this class project was implemented.

\section{References:}

[1] W. J. Askeland, D. R., \& Wright, "Introduction to Materials Science and Engineering," in Essentials of Materials Science \& Engineering, SI Edition., Cengage Learning, 2013, pp. 1-18.

[2] J. P. Mercier, G. Zambelli, and W. Kurz, "Materials," in Introduction to Materials Science, Elsevier, 2002, pp. 1-16.

[3] W. D. Callister and D. G. Rethwisch, "Introduction," in Fundamentals of Materials Science and Engineering: An Integrated Approach, 5th ed., Wiley, 2016.

[4] "Adopt-a-Material": A Case Study for Self-driven Learning Process for Undergraduate Students Paper presented at 2019 ASEE Annual Conference \& Exposition, Tampa, Florida. 
[5] D. R. Askeland and W. J. Wright, The Science and Engineering of Materials. Cengage Learning, 2016.

[6] https://grantadesign.com/education/ces-edupack/

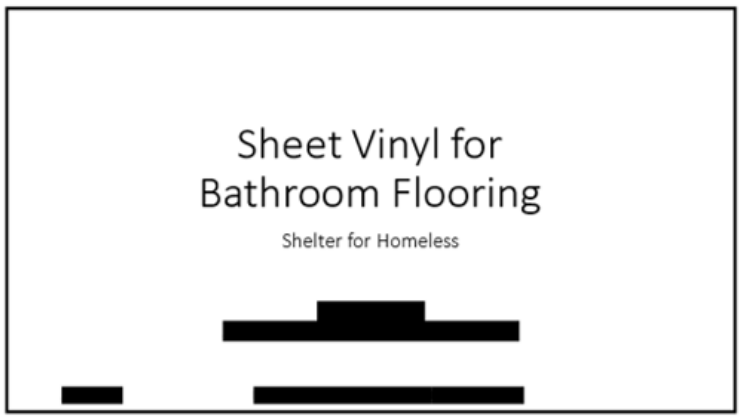

1

Project Overview Quad Chart (5 marks)

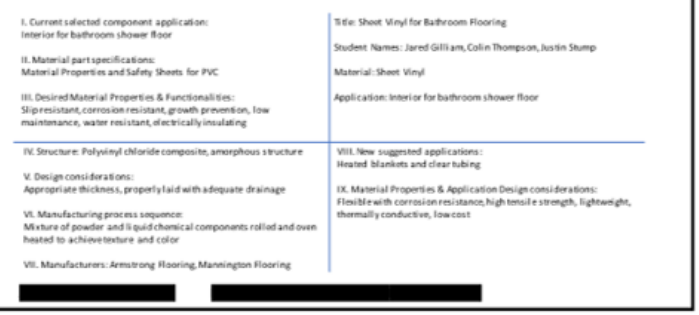

2

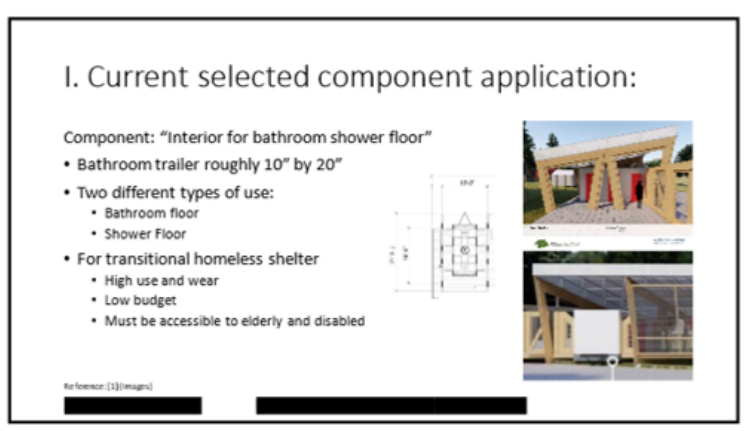

3

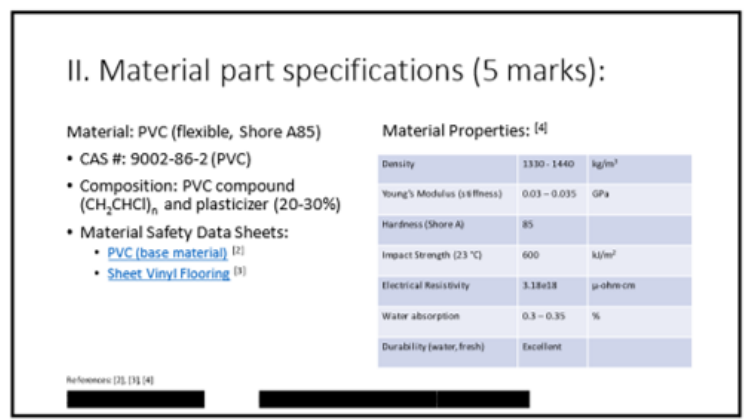

4

III. Desired Material Properties \& Functionalities (5 marks):

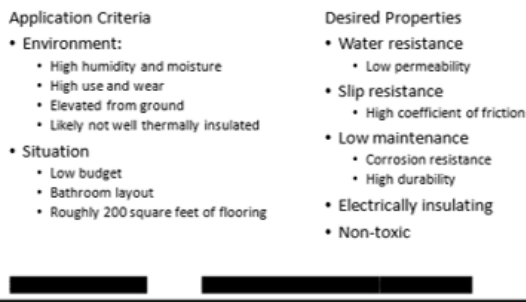

5

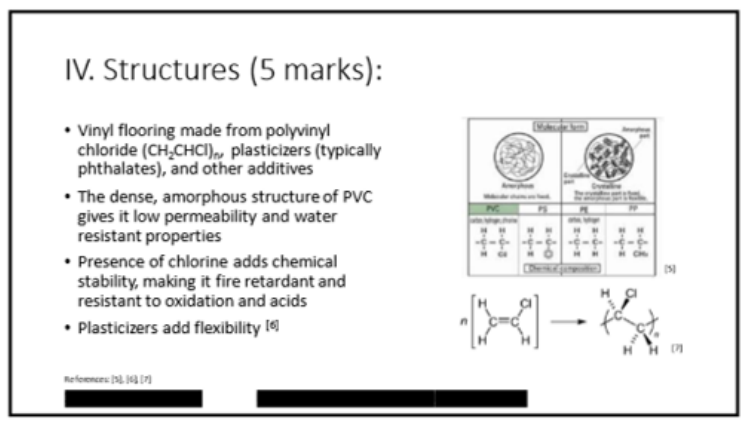

6

Figure 1: Sample project report 


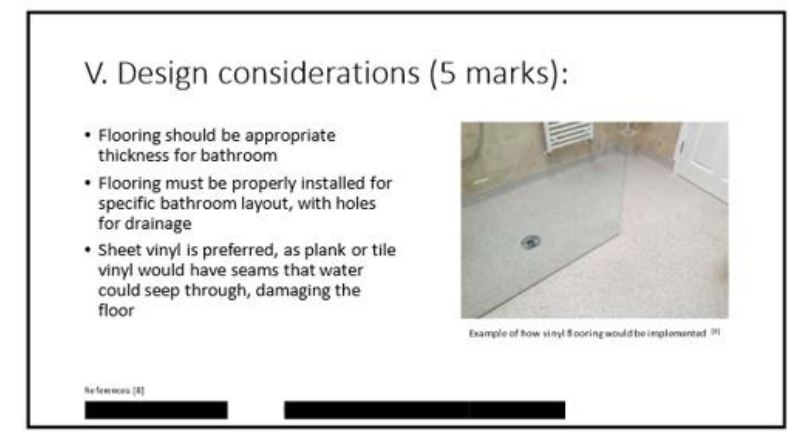

7

VI. Manufacturing process sequence (5 marks):

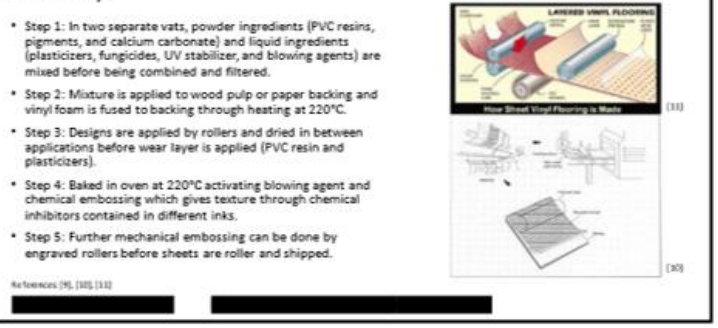

8

VII. Manufacturers and pricing (at least 2; 5 marks):

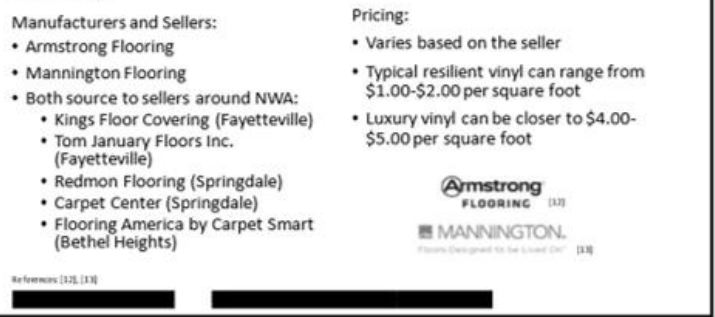

VIII. New suggested applications (at least two; 5 marks):

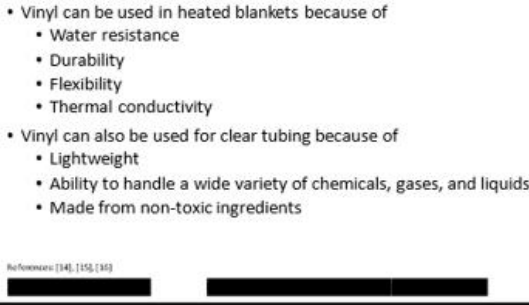

10

IX. Material Properties \& Application Design considerations (10 marks):

- Price: \$2.64-3.04 per kg

- Tear Strength: 76-80 N/mm

- Thermal Conductivity: $0.16-0.2 \mathrm{~W} / \mathrm{m}^{* 0} \mathrm{C}$

- Fracture Toughness: $1.49-1.54 \mathrm{MPa}^{*} \mathrm{~m}^{\wedge} 0.5$

- Tensile Strength: $19-20 \mathrm{MPa}$

- Flexural Modulus: 0.03-0.035 GPa

- Flexural Strength: 20-21 MPa

- Recyclable

- Excellent in fresh and saltwater

mempisiany

11

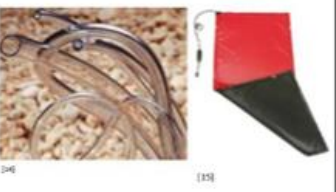

(1):

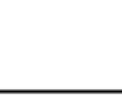

References

11 Ches

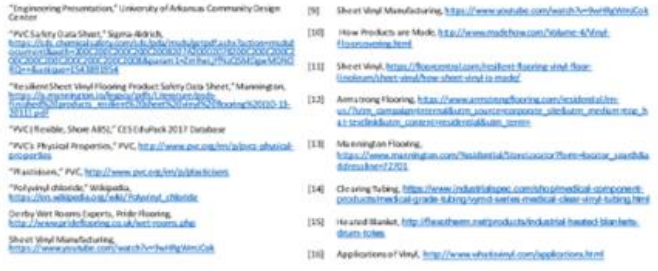

12

Figure 1(continued): Sample project report 